\title{
HIGH FIDELITY SIMULATION IN NURSING EDUCATION: CONSIDERATIONS FOR MEANINGFUL LEARNING
}

\author{
Anna-Marie Welman, Cynthia Spies
}

\begin{abstract}
High fidelity simulation within nursing education continues to gain momentum. In sub-Saharan Africa vast amounts of money are invested towards the implementation of simulation to complement nursing education. Since the use of simulation is a fairly new addition to nursing education in developing countries, contextual research is necessary to ensure meaningful implementation in educational programmes. To meet the need for such research, two researchers explored the use of high fidelity simulation in a nursing school at a higher education institution in South Africa. The aim of the article was to discuss the insights gained on what students appreciated most about the high fidelity simulation learning experiences and what aspects should be improved to make the learning experience more meaningful. Qualitative data were gathered by means of focus group interviews, a module evaluation questionnaire and the nominal group technique. The unit of analysis comprised of baccalaureate and post-registration nursing groups.
\end{abstract}

From the data collected two broad categories emerged, namely students' unpreparedness and aspects that students valued in terms of simulation. Unpreparedness was related to emotional, theoretical and technical aspects of simulation. Students appreciated the authenticity and psychological safety of the simulation learning experience.

To create meaningful learning experiences for students, it was recommended that a detailed orientation programme be provided. Orientation aspects should include the functions of high fidelity simulators and equipment used during simulation sessions. Students should be allowed to spend as much time as they need to familiarise themselves with the simulation environment. Educators should ensure that students understand the expected outcomes of simulation sessions and provide them with detailed information about simulation events. An agreement, whereby students and educators concur to maintain confidentiality about simulation and debriefing events should be included, since it enhances the psychological safety that students experience. It is important, through feedback, to rectify the mistakes that students make, but this should be done in a respectful manner, allowing students to share their experiences in a safe debriefing environment

Keywords: High Fidelity Simulation; Simulation-based learning; Authenticity; Simulation unpreparedness; Psychological safety 


\section{Introduction and problem statement}

Countries worldwide are looking for better ways to educate health professionals and organise their educational systems. In sub-Saharan Africa, a significant investment was made to support sustainable high quality nursing education through innovative educational strategies, including simulation. As a component of the Columbia University ICAP Nurse Capacity Initiative (INCI), the Nursing Education Partnership Initiative (NEPI) was established to assist nursing schools in several African countries (Lesotho, Malawi, Zambia, Ethiopia and the Democratic Republic of Congo) with much needed transformative educational strategies. In an effort to equip nurse educators from various nursing schools in the first four countries mentioned above, simulation-based teaching and learning workshops were presented to equip them with the necessary background knowledge and skills to implement simulation as a learning strategy within their curriculum.

Extensive research has already verified that simulation is an effective learning strategy. Simply stated, simulation is the act of imitating the behaviour of a specific situation or process by means of something suitably analogous for training purposes (Nel, 2010). Gaba (2007), whose conceptual definition of simulation is most often quoted, emphasises that "simulation is a technique, not a technology, to replace or amplify real experiences with guided experiences, often immersive in nature, that evoke or replicate substantial aspects of the real world in a fully interactive fashion" (Gaba, 2007).

The advantages that the implementation of simulation-based teaching in the nursing curriculum holds have been well established. Lasater (2007) has stated that the integration of simulation into the curriculum of nursing students will help them to develop their critical thinking and clinical judgement abilities and function more effectively in the clinical setting. In terms of skills development, it was found that students who engaged in simulation acquired skills faster than those who were trained through traditional education practices (Garrett, Macphee \& Jackson, 2010). Additionally, simulation places the needs of the students at the centre of attention and creates a 'perfect' teaching opportunity (Kneebone, 2005).

Simulation is often referred to as ranging from low to medium to high fidelity, where fidelity denotes the degree to which the real world is reproduced or imitated (Page, cited in Riley, 2008; Rothgeb, 2008). A recent in-depth literature review brought to light Paige and Morin's (2013) description of simulation fidelity as a matrix consisting of three dimensions: physical, psychological and conceptual. The physical dimension is associated with equipment and environmental attributes. Equipment, for example, is characterised by the level of mannequin technology, whereas environmental attributes are characterised by the appearance and layout of the simulated setting. The psychological dimension reflects students' perceptions in terms of how believable the representation of reality is, which is closely linked to how students will engage in, and experience, the simulation (Paige \& Morin, 2013). The level of the student's psychological engagement will be affected by the authenticity of events or tasks during the simulation encounter, and whether the scenario reflects real situations as closely as possible. The conceptual dimension refers to how students connect theoretical concepts to actual events during the simulation 
encounter. For example, if the scenario is about managing a patient in a state of shock, but the 'patient' displays a very high blood pressure and a strong pulse, a student might become confused or fail to interpret that as a state of shock because, shock is often accompanied by low blood pressure and a weak pulse. This difference between the scenario and the real situation could lead to a negative transfer of knowledge and should be avoided.

Ideally, high fidelity simulation (HFS) should include a full-bodied, computer-driven mannequin (highlevel equipment) in an environment that resembles a particular healthcare setting as closely as possible (high-level environment). In addition, lifelike scenarios assist students in experiencing optimal immersion where they will, for example, experience strong emotions and have to apply their, values and beliefs during the learning experience (high-level psychological engagement). Finally, to achieve high-level conceptual fidelity, well-written scenarios ensure that the simulation activity represents actual nursing problems: for example, a patient with cardiovascular dysfunction or burn injuries. In this way, students can develop clinical reasoning skills when they are required to connect theoretical concepts to real-life situations.

\section{Problem statement}

Continuous efforts by many scholars and researchers in education have resulted in the development of a sound foundation with regard to the science and practice of simulation in nursing education. A wellknown example is the simulation framework developed by Pamela Jeffries in 2005. This framework proved useful in the design, implementation and evaluation of simulations used for teaching in nursing education (Jeffries, 2005). In sub-Saharan Africa, however, the subject of HFS in healthcare is regarded as a fairly new addition to educational programmes. Few educators have hands-on experience of incorporating simulation-based learning into their curricula. Although many educators in healthcare realise the value of simulation-based training, educators and students find simulation experiences daunting. Limited research is available that shares the students' perspective on the implementation process.

The research on which this article is based was aimed at gaining insight into the use of HFS in a nursing school at a higher education training institution in South Africa. Two researchers explored the HFS learning experiences of students. The purpose of this article was to reflect on what students appreciated about their HFS learning experiences and what aspects should be improved in order to make this kind of learning experience more meaningful.

The process of implementing HFS at the nursing school was initiated by a workgroup consisting of the educators and preceptors responsible for the teaching of Baccalaureate and post-registration nursing students. They had to plan the simulation objectives, learning activities and simulation scenarios based on the course and module outcomes. Once these were available, the HFS coordinator and a technical team were able to prepare the simulation environment. Prior to the simulation experiences, students were theoretically prepared for the content of the theme on which the scenario was based, for example 
through class activities and clinical demonstrations. Specific workbook activities had to be completed as part of their class preparation.

A simulation experience usually commences with a pre-simulation briefing session during which students are oriented towards the clinical case and their assigned roles. The simulated scenario is then presented, followed by a debriefing session that is facilitated by an educator who observes the video-recorded learning experience from the control room.

\section{Methodology}

Qualitative data were gathered from two different sources (Baccalaureate and post-registration students) by means of three methods. Four focus group interviews were conducted with the Baccalaureate students and they completed a module evaluation questionnaire. The nominal group technique was used to gather data from the post-registration students. Ethical approval to conduct the research was obtained from the ethics committee of the higher education institution in question. Permission for the research was granted by the relevant authorities.

\section{Population and unit of analysis}

A total of 35 Baccalaureate and 21 post-registration nursing students from the nursing school constituted the population. The sample size consisted of 23 Baccalaureate and 14 post-registration nursing students who volunteered to participate. All participants met the inclusion criteria of having participated in at least two HFS learning experiences.

\section{Data gathering}

Expert moderators facilitated the data-gathering sessions. One moderator facilitated the four focus group interviews and another facilitated the nominal group. Participants were oriented regarding the purpose of the research and the data-gathering technique and informed consent was obtained from all participants. informed consent was also obtained from participants in relation to the use of an audiorecorder. The research question posed during the focus group interviews was: "Describe your learning experience of the high fidelity simulation with one patient who had had a myocardial infarction and the other who suffered from hypovolemic shock." This unstructured focus group interview approach was indicated since the interests of the participants were prioritised. Data from the first interview were used because relevant responses were elicited. The audio-recorded data were transcribed and electronically captured. The Baccalaureate students were requested to complete a module evaluation questionnaire which included open-ended questions pertaining to their simulation learning experience. The questionnaire was administered electronically and completed anonymously.

In the nominal group, the moderator requested the students to "write down suggestions to improve your learning during a simulation experience". Although the participants voted to determine the priorities, only the responses generated during the nominal group discussion were included for the purpose of this article. 
Credibility of data was enhanced through prolonged engagement with participants which enabled the researchers to gather rich data. In order to validate the data, member checking was done. Member checking is inherent to the nominal group technique, but was intentionally implemented with the focus group participants. Equivalence was ensured by using one experienced moderator per data-gathering method.

\section{Data analysis}

All narrative data obtained from the three data gathering methods were combined. Open coding was done collaboratively by the two researchers.

\section{Results}

Two broad themes emerged from the data gathered; namely, (1) the unpreparedness that the students felt and (2) the aspects that they valued in terms of their simulation experience. From the themes related categories were identified. Figure 1 shows that the categories related to the first theme reflect the students' emotional, theoretical and technical unpreparedness. The second theme identified, as its categories, authenticity of the simulation experience and the students' sense of psychological safety in this situation. Each theme and the related categories are discussed under the results section.

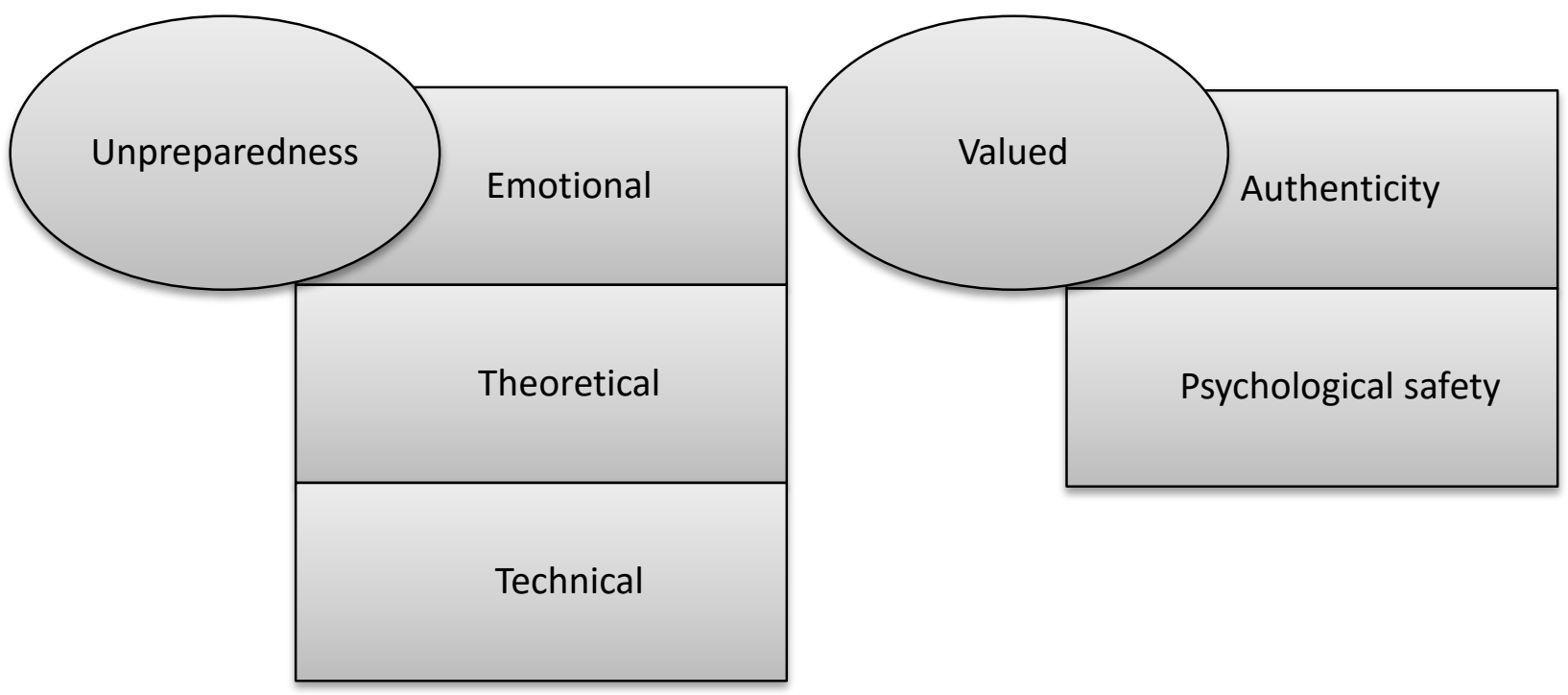

Figure 1: Summary of themes and related categories to explain high fidelity simulation learning experiences of students

\section{Discussion}

Since a large number of responses contributed to the identification of the themes and categories listed above, only selected examples are included in this article. Transcripts of responses are available on request from the corresponding authors. 


\section{Unpreparedness}

The planning and running of HFS sessions are time-consuming and require meticulous preparation. While participation in simulation sessions can be an enriching and valuable experience, sloppy preparation of these sessions, or sessions that do not mimic reality as closely as possible, can have a potentially negative effect on student learning and their experience of HFS and this must be avoided at all costs (Alinier, 2011; Miller, Leadingham \& Vance, 2010). However, there is limited evidence-based research that clarifies aspects such as setting up the simulation laboratory, preparation of the role-players and creating authentic scenarios (Sanford, 2010).

Proper preparation for learning constitutes the basic building blocks of foundational knowledge. In his taxonomy of significant learning, Fink (2003) defines knowing as the student's ability to remember and understand specific information and ideas. This foundational knowledge provides the basic understanding that is required for application of knowledge to occur. Application of learning permits students to develop certain skills and to learn to manage complex situations. A student who does not know what to learn or where to find the information cannot learn, thus preventing the formation of foundational knowledge and its application.

Emotions are intimately intertwined with almost every aspect of the teaching and learning process and play a vital role when students engage in academic activities (Schutz \& Lanehart, 2002; LinnenbrinkGarcia \& Pekrum, 2011). The emotional responses of participants before engaging in simulation could influence their perception of learning (Prion, 2008). Where negative emotions are present, learning is adversely influenced, as was evident in the research described in this article. The emotional unpreparedness experienced by the students is discussed below.

\section{Emotional unpreparedness}

Even though the students were oriented regarding the features and functions of the mannequin, its environment and the video-recording, the simulation experience was new and they did not know what to expect. This situation elicited emotional responses as follows:

- It was a bit scary at first because you can't expect a doll to respond, you know.

- It made me extremely anxious! Extremely! Because I was on the defibrillator with the cardio one and I didn't know what I was doing. I had no idea. So, ja, it just made me anxious.

- $\quad$ Practice session before simulation to ease tension.

- In the beginning the cameras must be off.

- $\quad$ Spectators must be less - only one lecturer.

Trying to deny the presence of emotions during learning is an unproductive exercise, since emotions form an integral part of any educational activity. Educators should realise that it is not always possible to control the emotional reactions of students (Schutz \& Lanehart, 2002). Although this is true, measures to manage the effect of emotions during simulation must be carefully planned and implemented. 
Simulation educators must be realistic in their expectations of students and their performance abilities. An example would be not to create stress in students by telling them that 'they may not make mistakes'.

When simulation sessions are video-recorded, students feel unsafe, which leads to increased anxiety. Students become anxious because they feel exposed and are afraid that they will be embarrassed in front of their peers. In order to lower the students' feelings of fear and anxiety, no extra observers should be allowed to watch during the simulation session as it makes students feel uncomfortable (Henneman \& Cunningham, 2005).

The students need to discuss the causes and effect of emotions experienced during the simulation and voiced during the debriefing session. The importance of having skilled educators to facilitate the debriefing session cannot be stressed enough (McCaughey \& Traynor, 2010). It is thus necessary to ensure that the educators responsible for debriefing receive training in this area.

\section{Theoretical unpreparedness}

Being unprepared includes not having the requisite skills or complete knowledge of the scenario (Ganley \& Linnard-Palmer, 2010). The students understood that they would be performing activities related to the content of the module, but were unsure of what these would be and did not understand the integrated nature of the simulation or that they had to care holistically for the simulated patient by applying their theoretical knowledge:

- We didn't know what is it that you have to prepare actually. What am I going to be doing in there? I had no idea. So for me, it's like ... that's why I'm saying I was not prepared ...

- And another thing to add on that is that we knew the theory part of myocardial infarction and hypovolemic shock, so we were asking ourselves, because the educator said it is an active class ... the simulation. So you're asking yourself: how are they going to put this in a practical way?

For HFS to have maximum educational value, the development of appropriate and well-planned scenarios is essential. Ideally, scripts for each scenario must correspond with learning outcomes and provide students with cognitive, psychomotor and affective learning experiences (Rothgeb, 2008; Alinier, 2011). Where students are exposed to simulation for the first time, less complex scenarios should be presented. As students become accustomed to the learning experience, more complex events can be created.

Participants suggested that the simulation patient scenario should be provided to them in advance, which correlates with literature indicating that students are empowered to prepare thoroughly for the simulation if the patient scenario is provided a day before the time (Ravert, 2010):

- $\quad$... at least if they tell you the day before to prepare for simulation it would have been better.

- $\quad$ Provide a hand-out of what is going to happen on the simulation day. 
Since the technical features of the HFS can be something that students will either enjoy or find disturbing, students need to be prepared on what to expect and how abnormalities will be presented. This point leads to a discussion on the technical unpreparedness that was reported in the research.

\section{Technical unpreparedness}

Effective technical preparation includes a hands-on orientation at the bedside of the High performance simulator (HPS), since students have to familiarise themselves with the monitor, the HPS and the environment (Rhodes \& Curran, 2005; Wallin et al., 2007). It is important for educators to understand the limitations of the simulator and realise that a degree of imitation will always be present. Even though the HPS is designed to represent the features of real patients, it differs from reality and students should know how abnormalities will be presented in the mannequin. Some of their responses indicate that they were unprepared for the technical aspects of the HPS:

- We didn't expect the doll to respond. When he was responding, saying: 'I have chest pain,' 'I felt nauseous' and everything.

- Visit the simulation room and environment beforehand.

- $\quad$ Check if equipment is in working condition.

- $\quad$ Remove unnecessary equipment and make sure that the necessary equipment is available that will be used in the simulation session.

\section{Valued aspects about simulation}

The authenticity of the simulation environment is determined by the available stock and equipment. Having functional equipment such as a defibrillator, oxygen, stethoscopes, syringes, needles, medication and patient monitors available enhances the environmental realism of scenarios. The aspects that were valued by the participants included the authenticity and the psychological safety of the learning experience.

\section{Authenticity}

Simulation scenarios should be realistic and represent the actual clinical practice (Kneebone, 2005). As mentioned in the introduction, factors influencing simulation realism include fidelity, equipment, the environment and the psychological reaction of participants. Students valued the realism of the HPS, as illustrated by the responses quoted below:

- $\quad$... is baie naby aan die werklikheid. Veral omdat ... want jy kan polse voel. Jy kan sien hoe die borskas uitsit. (... is very close to reality. Especially because ... because you can feel pulses. You can see the chest expanding.)

- $\quad$...maagklanke hoor. Dit maak dit baie realisties en dit bring ons baie naby aan wat werklik gebeur in die praktyk. (... hear intestinal sounds. This makes it very realistic and brings one very close to what really happens in practice.) 
- $\quad$ Of hy sê sy bors is seer. So jy moet nou reageer daarop, want hy is half'n regte mens ... (Or he says he has chest pains So you must react to this, because he is sort of a real person ...)

- It was like a real, real patient. With the monitors and everything.

The unique, immediate feedback mechanism of the HPS during simulation is advantageous and allows students to see the outcomes of their actions as they occur (Rauen, 2004). The students agreed that the instant feedback they received enhanced the realism of the situation and allowed deeper insight into the precision of their actions:

- Now when you come to the doll that responds, at least you know what you are doing. You know what you are doing right, you know, okay, that is wrong and he's gonna die. Not like that doll, the one that does not respond you don't know if he is really dead or not.

In an effort to enhance the realism of the simulation, the students were requested to dress as they would for their practicum placements. In accordance with Kesten et al. (2010), the wearing of uniforms during simulation is encouraged, since this allows students to interact with the simulator as if it is a real patient. It is the researchers' view that this practice encourages professional behaviour from students:

- We also do feel like professionals because when we are doing our simulation, you are in your uniform and everything ... You do feel like a sister. It is a very good thing that we do have to wear our uniforms.

An aspect that added to the realism of the simulation was the interaction within the team. It is often assumed that communication and teamwork skills come naturally to nurses, but this is not the case (Holtschneider, 2007). Through simulation, student nurses are able to improve their teamwork skills and practise their collective nursing actions (Wallin et al., 2007):

- En dan ook om in 'n span saam te werk. Want ons was hierdie groot groep mense wat saam moes werk. (To work together in a team. Because we were this large group of people that had to work together.)

McCaughey and Traynor (2010) found that $71 \%$ of their participants agreed that their value as a member of the healthcare team was enhanced as a result of participating in a simulation. In accordance with this view, a student in the current research felt that the simulation allowed her to find her place within the team:

- It also helped me in a sense that it gave me confidence to act part of the healthcare team, be able to help where I could.

The high levels of realism allowed the students to engage actively during the scenario, suspend disbelief and implement interventions that could improve the condition of the simulated patient (Yaeger et al., 2004). 
The allocation of a role and certain responsibilities to each team member forms part of the measures to enhance the effectiveness of clinical teams. The realism of teamwork was confirmed by a student who described her experience of a similar patient crisis situation that occurred during her practicum rotation and she explained how the different role allocations became clear to her:

- It is, because I remember in, in ... I was working in KTE (cardio-thoracic unit) and then we had to, okay, some patient collapsed. I didn't know about this whole leader and that there is supposed to be a leader ... the matron was the leader that time and the other one was writing. I was just like, okay, what are they writing and then when I got there, now I got an idea of okay, they were writing these things on how the whole process went and stuff.

It would be preferable to expose students to these emergency situations in simulation before they enter the clinical areas, since simulation allows students to experience the same cognitive and behavioural processes that will be utilised while in practice (Salas et al., 2008). This is not always possible, since the ICU placements and the teaching of the content do not always occur simultaneously. However, it is clear from the comments that some students were able to link what happened in the scenario with a situation that transpired during their practicum placement. This confirms that adults learn through experience (Bruce, Klopper \& Mellish, 2011).

The students acknowledged the allocation of a role to each member as a constructive aspect. They felt that it enhanced their overall experience of the simulation positively and created order. Team nursing as it occurs in clinical practice was replicated:

- Every member of the team has to have a job. Not all of us can go to fetch adrenalin. 'Cause one is allocated for medication and one for breaths and for compressions and stuff.

- $\quad$ Each member of the simulation group should know beforehand which role he or she will play and what is expected of each role.

The students realised the importance of teamwork and felt that the simulation had assisted them in developing this skill.

\section{Psychological safety}

The psychological needs of students during learning include the need for safety, acceptance, affection and achievement. Cioffi (2001) mentions that HFS allows students to learn without fear for their personal or patient's safety. By creating a real but safe simulation environment, students will be able to suspend their disbelief and immerse themselves fully in the experience.

Another response from the students was that although the simulation felt real, it was safe for them to make mistakes, thus confirming the low-risk nature of the HFS (Lasater, 2007). Through simulation, students are permitted to review the good or bad decisions they make, without causing harm to an 
actual patient (Gates, Parr \& Hughen, 2012). Some of the students' views on this matter were the following:

- If you make a mistake, no one's life is at stake. No... Nothing is like, set in stone, you know. You can just reset the machine again.

- $\quad$ Sonder dit, maak mens die foute op regte pasiënte. (Without it mistakes are made on real patients.)

The safety of the HFS was enhanced by requesting the entire class to sign a confidentiality agreement before being exposed to the simulation. This prevented them from sharing the HFS experience with people who did not have any interest in the actions that transpired (Johnson-Russell \& Bailey, 2010). Even though taking part in the simulation caused the students to feel excited, they knew that they could not share the specifics of the simulation or debriefing session with others:

- I like also the confidentiality part of it, where you have to sign the confidentiality form ... It is between us ... So ja, I really think that it is good that the confidentiality things are remaining between us. Like, when you go there, you don't have to be, to feel anxious, like worried, like oh my word, the whole school is gonna know I didn't know how to do this.

- Because I was so ... After the simulation I was so excited, I wanted to go call my mother and tell my friend what happened. And it was like, oh the confidentiality thing. Now I can't. Now it's like I have to keep it to myself. The interesting part of what happened. Nah, okay, I'll just keep quiet.

At first, the students were afraid that they would be judged on the mistakes they made and publicly humiliated in front of peers, but during the debriefing session they realised that this would not be the case. Henneman and Cunningham (2005) identified a safe psychological environment as a prerequisite for effective reflections. During the debriefing, for a student to acknowledge that he or she has made a mistake requires courage and such a situation can be facilitated by the educator taking a 'stance of genuine curiosity,' which changes the mistakes into puzzles to be solved and not serious errors (Rudolph et al., 2006). The identification of mistakes is important, but students should never leave the debriefing room without knowing how to correct them.

Linked to the fact that the students were willing to admit their mistakes publicly is that they were assessed by their peers and not by the educators. Peer assessment is defined as the assessment of a student by his or her peer group, and this form of assessment is used for feedback and not as formal assessment (Hughes \& Quinn, 2013). The following excerpt emphasises the value of peer assessment:

- I love that part where you like watching that video and you like: 'No man XXX, why did you do that? Why?' You know. You still correct yourself. No one told you that XXX was supposed to do that, but you could see that that was wrong.

The students said that they had learnt from each other's mistakes that were made. This is in agreement with the view that learning occurs as a result of the interaction between peers while engaged in practice (Kneebone, 2005). 


\section{Conclusion}

Insights gained from the students' HFS learning experience assisted the authors in making recommendations towards maximising learning and the value of simulation-based education.

With regard to preparing students for HFS learning, it seems imperative to equip them with the prerequired background knowledge and skills applicable to the specific scenario (Alinier, 2007). Although an effort was made to provide the students with the theoretical background applicable to the simulation scenarios, they were neither emotionally nor technically sufficiently prepared for the learning experience. Consequently, the students felt unprepared and some of them experienced the simulation experience as being negative because they felt academically unsafe. The unpreparedness caused a deflated self-confidence level, dissatisfaction with own performance and negative reactions to current and future simulations in some of the students (Prion, 2008).

The authors agree with the view of Alinier et al. (2006) mentioned above, and recommend the prior development of a standardised orientation programme which should include aspects like orientating educators and students regarding the use of the HPS, what to expect during the session, as well as details regarding the environment and equipment. It is further recommended that the scenario, the outcome for the session, the patient information, as well as a written explanation of each role should be provided to the students a day before the simulation (Henneman \& Cunningham, 2005; Horan, 2009; Reilly \& Spratt, 2007; Seropian, 2003). An illustration of how the video material is used during the debriefing sessions needs to be included and a video of a previously recorded simulation or an example from the internet should be shown (Yaeger et al., 2004).

Furthermore, it is emphasised that students will only share experiences and admit mistakes if they feel safe and know that the information that is shared remains confidential. A sense of safety is created through signing the confidentiality agreement and the students agreed that it is a good practice to uphold, as it also gave them a sense of control of the situation. Confidentiality aspects should include the patient information, video-recorded material and all discussions between educators and students during the simulation and debriefing sessions.

It is important, through feedback, to correct the mistakes that students make. The best practice guidelines on the professional integrity of students highlight the importance of receiving and providing constructive feedback (Gloe et al., 2013). Messages should be communicated in a clear and concise manner and feedback delivered immediately and respectfully.

The students indicated that they were able to learn through the mistakes made by their peers. Through reflection and by acting as facilitators, educators can enable students to discover the answers they need. This student-centred approach implies that students are allowed to ask and answer each others' questions. 
Although HFS is a time- and work-intensive practice, the benefits of this learning strategy outweigh its limitations. The following quote by one of the focus group interview participants confirms the positive impact that the HFS had on the students in this research and its ability to better prepare students for their practicum placements:

It was an awesome experience. We really learnt a lot from it: it helped to better equip us with the necessary skills and knowledge we need when confronted with the similar situation in the hospital setting.

\{Begin box\}

\section{Declaration of conflict of interest}

The authors declare no potential conflicts of interest with respect to the research, authorship, and/or publication of this article.

Partial funding for the completion of the research with the Baccalaureate nursing students was received from the University Based Nursing Education South Africa (UNEDSA) programme. Both authors are employed in the School of Nursing at the University of the Free State.

$\{$ End box 


\section{References}

Alinier, G. 2007. A typology of educationally focused medical simulation tools. Medical Teacher 29: e243e250.

Alinier, G., Hunt, B., Gordon, R. \& Harwood, C. 2006. Effectiveness of intermediate-fidelity simulation training technology in undergraduate nursing education. Journal of Advanced Nursing 54 (3): 359-369.

Bruce, J.C., Klopper, H. C. \& Mellish, J. M. 2011. Teaching and Learning the Practice of Nursing. 5th Edition. Cape Town: Pearson Education.

Cioffi, J. 2001. Clinical Simulations: development and validation. Nurse Education Today 21 (6): 477-486.

Fink, L. Dee. 2003. Creating Significant Learning Experiences. San Francisco: Jossey Bass.

Gaba, D.M. 2007. The Future Vision of Simulation in Healthcare. Simulation in Healthcare 2 (2): 126-135.

Ganley, B. J. \& Linnard-Palmer, L. 2010. Academic Safety during Nursing Simulation: Perceptions of Nursing Students and Faculty. Clinical Simulation in Nursing e1-e9. Doi:10.1016/j.ecns.2010.06.004.

Garrett, B., Macphee, M. \& Jackson, C. 2010. High fidelity Patient Simulation: Considerations for Effective Learning. Nursing Education Perspectives 31 (5): 309-313.

Gates, M. G., Parr, M. B. \& Hughen, J. E. 2012. Enhancing Nursing Knowledge using High fidelity Simulation. Journal of Nursing Education 51 (1): 9-15.

Gloe, D., Sando, C. R., Franklin, A. E., Boese, T., Decker, S., Lioce, L., Meakim, C. \& Borum, J. C. 2013. Standards for Best Practice: Simulation Standard II: Professional Integrity of Participant(s). Clinical Simulation in Nursing 9: S12-S14.

Henneman, E. A. \& Cunningham, H. 2005. Using Clinical Simulation to Teach Patient Safety in an Acute/Critical Care Nursing Course. Nurse Educator 30 (4): 172-177.

Holtschneider, M. E. 2007. Better communication, better care through high-fidelity simulation. Nursing Management 38 (5): 55-57.

Horan, K. M. 2009. Using the Human Patient Simulator to foster Critical Thinking in Critical Situations. Nursing Education Perspectives30 (1): 28-30.

Hughes, S. J. \& Quinn, F. M. 2013. Quinn's Principles and Practice of Nurse Education. 6th Edition. Hampshire: Cengage Learning. 
Jeffries, P. R. 2005. A framework for designing, implementing, and evaluating simulations used as teaching strategies in nursing. Nursing Education Perspectives 26 (2): $96-103$.

Kesten, K. S., Brown, H. F., Hurst, S. \& Briggs, L. A. 2010. Acute Care for Advanced Practice Nurses. In: Nehring, W. M. \& Lashley, F. R. (eds): 233-271.

Kneebone, R. 2005. Evaluating Clinical Simulations for Learning Procedural Skills: A Theory-Based Approach. Academic Medicine 80 (6): 549-553.

Lasater, K. 2007. High fidelity Simulation and the Development of Clinical Judgement: Students' Experiences. Journal of Nursing Education 46 (6): 269-276.

Linnebrink-Garcia, L. \& Pekrum, R. 2011. Students' emotions and academic engagement: Introduction to the special issue. Contemporary Educational Psychology 36 (1): 1-3.

McCaughey, C. S. \& Traynor, M. K. 2010. The role of simulation in nurse education. Nurse Education Today 30 (8): 827-832.

Miller, C. L., Leadingham, C. \& Vance, R. 2010. Utilizing Human Patient Simulators (HPS) To Meet Learning Objectives Across Concurrent Core Nursing Courses: A Pilot Study. Journal of College Teaching and Learning 7 (1):37-44.

Nehring, W.M. \& Lashley, F.R. (eds). 2010. High Fidelity Patient Simulation in Nursing Education. Sudbury: Jones and Bartlett.

Nel, P.W. 2010. The use of an Advanced Simulation Training Facility to Enhance Clinical Psychology Trainees' Learning Experiences. Psychology Learning and Teaching 9 (2): 65-72.

Paige, J. B. \& Morin, K. H. 2013. Simulation Fidelity and Cueing: A Systematic Review of the Literature. Clinical Simulation in Nursing 9 (11): e481-e489.

Prion, S. 2008. A Practical Framework for Evaluating the Impact of Clinical Simulation Experiences in Prelicensure Nursing Education. Clinical Simulation in Nursing 4 (3): e69-e78.

Rauen, C. A. 2004. Simulation as a teaching strategy for Nursing Education and Orientation in Cardiac Surgery. Critical Care Nurse 24 (3): 46-51.

Ravert, P. 2010. Developing and Implementing a Simulation Program: Baccalaureate Nursing Education. In: Nehring, W. M. \& Lashley, F. R. (eds): 59-74. 
Reilly, A. \& Spratt, C. 2007. The perceptions of undergraduate student nurses of high fidelity simulationbased learning: A case report from the University of Tasmania. Nurse Education Today 27 (6): 542-550.

Rhodes, M. L. \& Curran, C. 2005. Use of the Human Patient Simulator to Teach Clinical Judgment Skills in a Baccalaureate Nursing Program. CIN: Computers, Informatics, Nursing 23 (5): 256-262.

Riley, R.H. (ed.). 2008. Manual of Simulation in Healthcare. New York: Oxford University Press.

Rothgeb, M. K. 2008. Creating a Nursing Simulation Laboratory: A Literature Review. Journal of Nursing Education 47 (11): 489-494.

Rudolph, J. W., Simon, R., Dufresne, R. L. \& Raemer, D. B. 2006. There's No Such Thing as 'Nonjudgmental' Debriefing: A Theory and Method for Debriefing with Good Judgment. Simulation in Healthcare 1 (1): 49-55.

Salas, E., Diazgranados, D., Weaver, S. J. \& King, H. 2008. Does Team Training Work? Principles for Health Care. Academic Emergency Medicine 15 (11): 1002-1009.

Schutz, P. A. \& Lanehart, S. J. 2002. Introduction: Emotions in Education. Educational Psychologist 37 (2): 67-68.

Seropian, M. A. 2003. General Concepts in Full Scale Simulation: Getting Started. Anesthesia \& Analgesia 97 (6): 1695-1705.

Wallin, C., Meurling, L., Hedman, L., Hedegard, J. \& Felländer-Tsai, L. 2007. Target-focused medical emergency team training using a human patient simulator: effects on behaviour and attitude. Medical Education 41 (2): 173-180.

Yaeger, K. A., Halamek, L. P., Coyle, M., Murphy, A., Anderson, J., Boyle, K., Braccia, K., Mcauley, J., De

Sandre, G. \& Smith, B. 2004. High fidelity Simulation-based Training in Neonatal Nursing. Advances in Neonatal Care 4 (6): 326-331. 